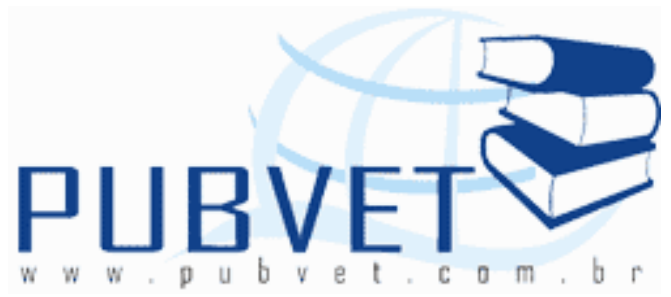

PUBVET, Publicações em Medicina Veterinária e Zootecnia.

Disponível em: <https://doi.org/10.31533/pubvet.v02n11a451>.

\title{
Alternativos em nutrição e alimentação de aves
}

\section{Daniel de Magalhães Araujo ${ }^{1}$}

1Zootecnista, Ms., Aluno de Doutorado em Zootecnia do Programa de Pósgraduação em Zootecnia da FMVZ/UNESP, Botucatu - SP.

\section{RESUMO}

A avicultura brasileira é, sem dúvida, o setor da produção animal mais moderno e eficiente do país, além de um dos mais competitivos em nível mundial. Certamente a capacidade dos nutricionistas de utilizarem a enorme variedade de ingredientes alternativos, dentre eles os aditivos, corrobora para este cenário. O uso de aditivos, como antibióticos (busca por substitutos), pró, pré- e simbióticos, enzimas e ácidos orgânicos vêm sendo bastante estudados na alimentação animal, pois podem contribuir na melhoria do desempenho animal e até mesmo possibilitar maior utilização de ingredientes alternativos. Nesta revisão são abordados aspectos gerais da utilização destes aditivos na alimentação de aves.

Palavras-chave: Ácidos Orgânicos, Enzimas, Prebióticos, Probióticos, Simbióticos 
Araújo, D.M. Alternativos em nutrição e alimentação de aves. PUBVET, Londrina, V. 2, N. 46, Art\#451, Nov3, 2008.

\section{Alternatives in avian nutrition and feeding}

\section{ABSTRACT}

The Brazilian aviculture is, without a doubt, the section of the production more modern and efficient animal of the country and, without a doubt, one of the most competitive in world level. Certainly the nutritionists' capacity of they use the enormous variety of alternative ingredients and of they be always attentive to the addictive ones available it corroborates for this scenery. The use of addictive, as antibiotics (for your substituition), probiotics, prebiotics and synbiotics, enzymes and organic acids are also being quite emphasized in the animal feeding and they can contribute in the improvement of the animal acting and even making possible larger use of the alternative ingredients.

Key words: Alternative feedstuff, Prebiotics, Probiotics, Synbiotics, Enzymes, Organic acids

\section{INTRODUÇÃO}

O grande dinamismo e arrojo da produção animal brasileira, principalmente no tocante à avicultura, dentre outros fatores, estão diretamente correlacionados à capacidade dos profissionais da nutrição animal de formular dietas de alta qualidade e a custo reduzido, como também a um setor empresarial empreendedor, eficiente e, portanto, bastante competitivo.

Para tanto, a utilização de modernos compostos, advindos da biotecnologia, é primordial, pois podem resultar em uso mais eficiente dos nutrientes e, portanto, reduzir os custos de produção.

$\mathrm{Na}$ criação de aves comerciais, a alimentação representa cerca de $70 \%$ do custo de produção. Neste contexto, de acordo com LUCHESI e JUSTINO (2003), em um programa de alimentação de frangos de corte (49 dias), cerca de $90 \%$ dos componentes são de origem vegetal, $9 \%$ de origem animal, $0,4 \%$ 
Araújo, D.M. Alternativos em nutrição e alimentação de aves. PUBVET, Londrina, V. 2, N. 46, Art\#451, Nov3, 2008.

de origem mineral e $0,6 \%$ premix (vitaminas, aminoácidos e aditivos), sendo que $12,7 \%$ dos custos são relativos às vitaminas e aditivos. Isto, de modo geral, se equivale para poedeiras e codornas.

Quando são utilizados, por exemplo, alimentos alternativos, na maioria dos casos, se consegue diminuir os custos com a alimentação, entretanto, os índices zootécnicos ficam comprometidos devido à piora da utilização da energia e/ou proteína destes ingredientes pelos animais, principalmente pela presença de fatores tidos como antinutricionais. Na tentativa de reduzir este comprometimento, alguns artifícios são utilizados, como a adição de enzimas exógenas, probióticos, prebióticos, simbióticos, antibióticos e ácidos orgânicos nas dietas, que pode auxiliar direta e/ou indiretamente $o$ animal a utilizar mais eficientemente os nutrientes contidos neste tipo de ingredientes.

A busca por alternativas, como os aditivos, na alimentação de aves é realidade constante e estudos são necessários para que possamos afirmar até que ponto eles podem ou não ser utilizados, e em que condições e dimensões são realmente viáveis.

\section{ANTIBIÓtICOS}

Além da vacinação, nenhum outro avanço em sanidade foi mais significativo que o desenvolvimento dos antibióticos. A vacinação permitiu o combate às infecções virais e os antibióticos às infecções bacterianas. Estes avanços tecnológicos modernos, empregados na produção animal, mudaram a indústria e proporcionaram grande eficiência à produção animal (COOK, 2004).

Logo após o nascimento, as superfícies e mucosas dos animais, que em condições fetais são estéreis, rapidamente sofrem colonização por diversos microrganismos, alguns úteis e outros nocivos. Os úteis são benéficos por contribuírem para os processos digestivos e absortivos, enquanto que os nocivos podem causar inflamações na mucosa intestinal, gerar metabólitos 
Araújo, D.M. Alternativos em nutrição e alimentação de aves. PUBVET, Londrina, V. 2, N. 46, Art\#451, Nov3, 2008.

tóxicos e propiciar o aparecimento de enfermidades (SILVA e NÖRNBERG, 2003).

Para combater a proliferação dos microorganismos patogênicos e sua ação antagônica à produção, durante muitos anos, vêem sendo utilizados antibióticos (Figura 1) em níveis subterapêuticos, como aditivos nas rações, gerando grandes benefícios na criação animal, expressos por uma melhora no ganho de peso, conversão alimentar e viabilidade. O benefício, em longo prazo, do uso de antibióticos tem sido notado também na melhoria da saúde e uniformidade do desempenho, sendo que a taxa de melhora no desempenho depende, além disto, do manejo da granja, exposição à patógenos, estresse ambiental, tipo da dieta, dentre outros (HRUBY et al., 2004). Isto ocorre, pois há a eliminação de microrganismos que competem com o hospedeiro pelos nutrientes (CORRÊA et al., 2002).

A microflora das áreas digestivas de aves tem o potencial de controlar estes microorganismos patogênicos, entretanto, no passado, o uso de antibióticos na alimentação para controlar patógenos pode ter prejudicado alguns componentes da microflora em desenvolvimento.

As práticas comerciais modernas, que não permitem o contato do pintinho com o ambiente natural, onde deveria haver a transferência da microflora, e práticas cada vez mais eficazes de higiene, também projetaram a eliminação ou o controle máximo de patógenos avícolas, dificultando, em contrapartida, o desenvolvimento da microflora benéfica (CHAMBERS e LU, 2002). Isto porque, por natureza, os anticoccidianos deprimem o desenvolvimento de parasitas, em contrapartida limitando o desenvolvimento da imunidade (HU et al., 2000).

Os produtores argumentam que o contato do pintinho com o ambiente natural, menos "estéril" que as incubadoras, aumentaria sua proteção imune, permitindo a antecipação da retirada de anticoccidianos, com economia nos custos com medicamentos (HU et al., 2000). 
Araújo, D.M. Alternativos em nutrição e alimentação de aves. PUBVET, Londrina, V. 2, N. 46, Art\#451, Nov3, 2008.

Atualmente são cada vez mais freqüentes questionamentos sobre o uso de antibióticos em rações para promover o desempenho de aves, em virtude da possível presença de resíduos na carne e ovos e por alterarem o balanço microbiano intestinal, contribuindo para o surgimento de resistência em patógenos humanos (SILVA et al., 2003; FRITTS et al., 2000), a "resistência cruzada".

Em alguns países, o uso de antibióticos em alimentos para aves foi proibido ou severamente limitado. Como resultado, a indústria avícola deve buscar - e já o tem feito - outros meios para a manutenção da saúde e desempenho animal sob as condições comerciais atuais de criação (FRITTS et al., 2000).

Uma possível alternativa a este problema refere-se ao uso de prebióticos (SILVA e NÖRNBERG, 2003; SANTOS et al., 2003), probióticos (LODDI et al., 2000) e enzimas que, se usados de forma eficiente, podem minimizar as prováveis perdas de desempenho com a retirada dos antibióticos promotores do crescimento das rações avícolas.

Neste contexto, várias categorias de promotores de crescimento alternativos emergiram. Estes devem possuir atributos de eficácia, economia e, em alguns casos, habilidade para tolerar o processo de peletização. Os aditivos de rações devem também atender as exigências de segurança alimentar (SILVA et al., 2003; HOOGE et al., 2003). Prebióticos, probióticos e simbióticos, por serem integrantes comuns do organismo animal, não trariam problemas à saúde humana, ao contrário dos antibióticos que, originalmente, não fazem parte do organismo. 
Araújo, D.M. Alternativos em nutrição e alimentação de aves. PUBVET, Londrina, V. 2, N. 46, Art\#451, Nov3, 2008.
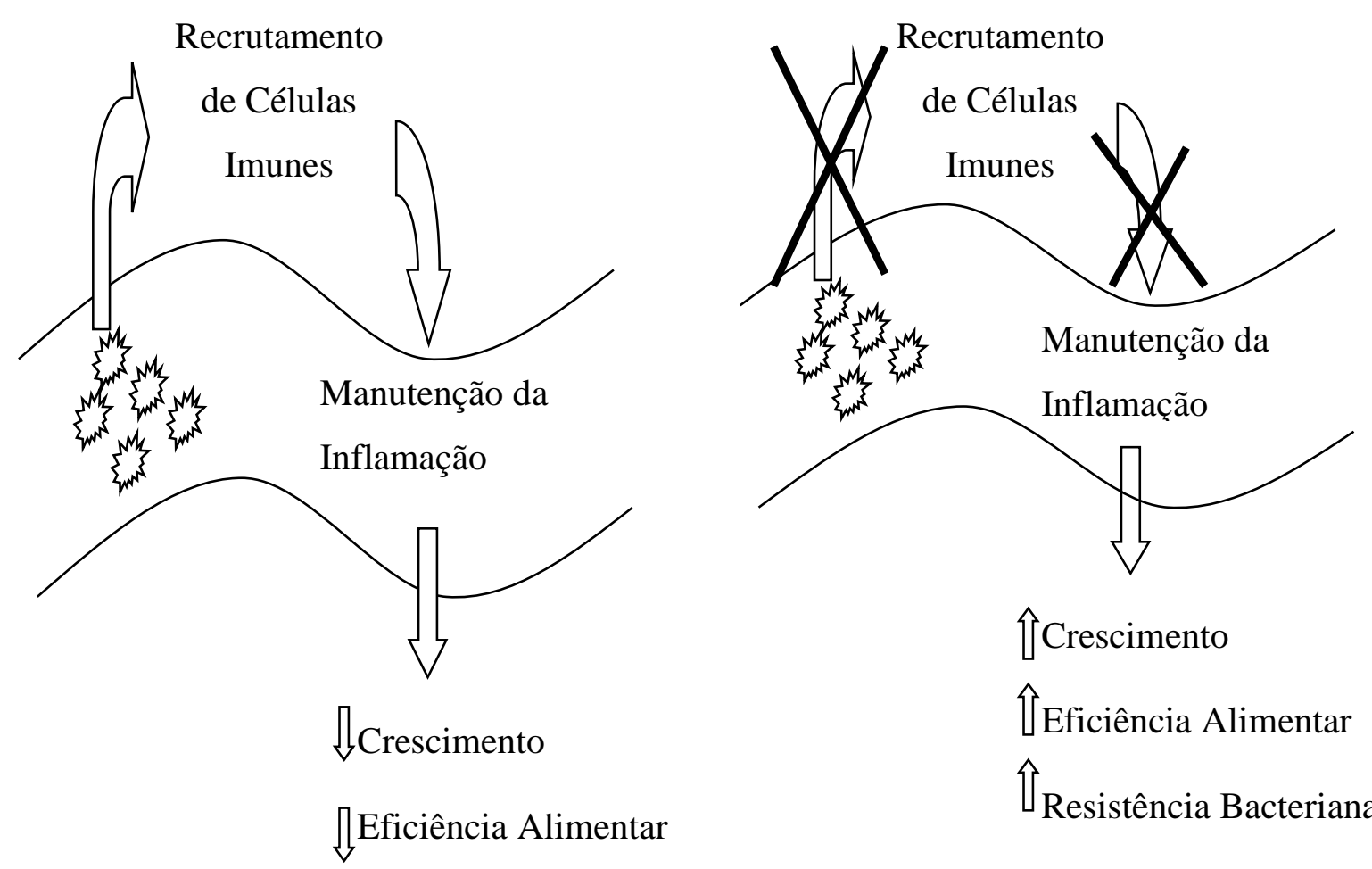

仓Crescimento

仓Eficiência Alimentar

$\widehat{\bigcup}_{\text {Resistência Bacteriana }}$

Figura 1 - Área gastrintestinal, perante desafio imune, em ambiente convencional sem antibióticos (esquerda) e com o uso de antibióticos (direita). Adaptado de COOK (2004).

Na "ausência" de bactérias gastrointestinais, devido à presença de antibióticos na dieta, a necessidade do recrutamento de células imunes para o intestino estão reduzidas e conseqüentemente, o desempenho animal é melhorado.

\section{PROBIÓtICOS}

Probióticos são microorganismos vivos, que geram benefícos quando introduzidos no trato gastrintestinal (TGI), competindo com a flora patogênica por nutrientes, locais de adesão no epitélio intestinal e sintetizando metabólitos (ácidos orgânicos) que criam resistência ao crescimento de organismos patogênicos. 
Araújo, D.M. Alternativos em nutrição e alimentação de aves. PUBVET, Londrina, V. 2, N. 46, Art\#451, Nov3, 2008.

Os probióticos promovem o equilíbrio da microbiota intestinal, além de melhorar o ganho de peso e a eficiência alimentar das aves, justamente por competirem com os patógenos no intestino e evitarem lesões no vilo, permitindo a regeneração da mucosa intestinal (SATO et al., 2002). Esta competição em que os microorganismos benéficos são favorecidos é importante, pois o desequilíbrio em favor de bactérias indesejáveis pode resultar em infecção intestinal, o que comprometeria a digestibilidade da ração.

\section{PREBIÓTICOS}

Prebióticos são oligossacarídeos não digeridos pelas enzimas endógenas do hospedeiro que, atingindo o intestino grosso, vão ser degradados pela microbiota benéfica específica, que cresce e combate os microorganismos patogênicos (SCAPINELLO et al., 2001).

Para uma substância ser classificada como prebiótico, ela não pode ser hidrolisada ou absorvida na parte superior do trato gastrointestinal, e deve ser um substrato seletivo para um limitado número de bactérias benéficas do cólon. Estas as quais terão crescimento e/ou metabolismo estimulados, sendo capazes de alterar a microflora intestinal favorável e induzir efeitos benéficos intestinais ou sistêmicos ao hospedeiro (DIONÍsIO et al., 2002).

A principal forma de ação dos prebióticos é sobre a modulação benéfica da microbiota nativa presente no hospedeiro e os efeitos resultantes do seu uso são evidenciados pelo crescimento das populações microbianas benéficas, pela melhora nas condições do lúmen intestinal, aumentando sua osmolaridade (IMMERSEEL et al., 2004), nas características anatômicas do TGI, promovendo o aumento da superfície de absorção da mucosa intestinal e no sistema imune e, em alguns casos, pela melhora no desempenho animal (SILVA e NÖRNBERG, 2003). 
Araújo, D.M. Alternativos em nutrição e alimentação de aves. PUBVET, Londrina, V. 2, N. 46, Art\#451, Nov3, 2008.

Os prebióticos mais importantes são hexoses; como glicose, frutose, galactose e manose; além de pentoses como ribose, xylose e arabinose (IMMERSEEL et al., 2004), sendo que frutose e manose são componentes dos dois mais importantes grupos de prebióticos utilizados atualmente: frutoligossacarídeos

(FOS) e mananoligossacarídeos (MOS), respectivamente.

Oligossacarídeos são cadeias longas de açúcares simples como manose ou frutose. Os FOS são produtos da indústria que, adicionados às rações, fornecem carboidratos fermentáveis para as bactérias benéficas nativas que habitam o trato gastrointestinal, minimizando as populações de bactérias patogênicas, como a Escherichia coli e Salmonella, por exclusão competitiva (SCAPINELLO et al., 2001). A exclusão competitiva é o fenômeno de inibição da proliferação dos microorganismos patogênicos pela adição de determinados compostos que favorecem a multiplicação dos microorganismos naturais benéficos do trato gastrintestinal do hospedeiro (IMMERSEEL et al., 2004).

Os FOS são utilizados como promotores de crescimento para Enterococcus faecium, Lactobacillus lactis e Pediococcus spp in vitro, porém, ainda não foi demonstrada a sua eficácia in vivo. Já os MOS possuem um mecanismo mais complexo. São derivados da parede celular interna de leveduras e seu primeiro modo de atuação é ligando-se a certas bactérias patogênicas na área gastrintestinal; essas bactérias ligadas aos oligossacarídeos não podem aderir à infecção iniciada no intestino, mas algumas bactérias não possuem em suas membranas celulares sítios de ligação para fixação dos oligossacarídeos, como por exemplo, a bactéria que causa a enterite necrótica no intestino (Clostridia). No entanto, a concentração desta bactéria é reduzida quando os MOS são administrados, o que demonstra seu segundo mecanismo de atuação, a modulação ou preparação do sistema imune para uma infecção (SCAPINELLO et al., 2001). 
Araújo, D.M. Alternativos em nutrição e alimentação de aves. PUBVET, Londrina, V. 2, N. 46, Art\#451, Nov3, 2008.

\section{SIMBIótICOS}

A combinação de probiótico e prebiótico é denominada de simbiótico e constitui um novo conceito na utilização de aditivos em dietas para aves (MAIORKA et al., 2001). Esta combinação entre probiótico e prebiótico poderia melhorar a sobrevivência do primeiro, pela disponibilidade do seu substrato. Isto resultaria em vantagens para o hospedeiro, tanto pela presença da flora benéfica quanto pela fermentação (IMMERSEEL et al., 2004).

\section{ENZIMAS EXÓGENAS}

Muitas vezes as enzimas endógenas não são produzidas em quantidades suficientes, sendo necessária a utilização de enzimas exógenas nas rações para melhorar a eficiência de utilização dos alimentos, promover a hidrólise dos componentes alimentares e tornar os nutrientes mais disponíveis para a absorção (SARTORI et al., 2002). Desta forma, melhora-se a digestibilidade e a disponibilidade de certos nutrientes para os animais, diminuindo a presença dos mesmos nas fezes e, conseqüentemente, a sua deposição no meio ambiente (COSTA et al., 2004). Além disto, possibilita maior utilização de ingredientes alternativos, diminui a variação da qualidade nutricional das dietas e reduz a incidência de fezes úmidas quando as aves são alimentadas com grãos de alta viscosidade (LESSON et al., 2000 e BEDFORD, 2000).

Além de suplementar a produção insuficiente de enzimas endógenas, específicas para determinados componentes alimentares, as enzimas exógenas são utilizadas também para fornecer aos animais enzimas que eles não conseguem sintetizar, como as celulases, reduzindo desta maneira, os efeitos negativos causados pelos polissacarídeos não amiláceos (PNAs) (FISCHER et al., 2002). Na tentativa de reduzir estes 
Araújo, D.M. Alternativos em nutrição e alimentação de aves. PUBVET, Londrina, V. 2, N. 46, Art\#451, Nov3, 2008.

efeitos, cellulases e hemicelulases são extensamente usadas em dietas ricas em PNAs para animais monogástricos (PONTE et al., 2004b). Estas enzimas melhoram o valor nutricional das dietas com alta concentração de PNAs, como aquelas à base de trigo, cevada e ervilhas (PERSIA et al., 2002; CAFÉ et al., 2002).

Entendendo estes efeitos e o mecanismo de ação dos inibidores biocatalíticos, podem-se desenvolver estratégias modernas para aumentar a eficiência catalítica das enzimas exógenas na nutrição animal (PONTE et al, 2004a).

Como a utilização de enzimas nas dietas, inicialmente, tinha como objetivo principal a redução da viscosidade da digesta no TGI, pouco interesse foi direcionado ao uso de enzimas para as rações à base de milho e farelo de soja, considerados ingredientes de baixa viscosidade (PUCCI et al., 2003). Entretanto, FISCHER et al. (2002) afirmaram que, atualmente no mercado, existem enzimas destinadas às rações para animais contendo matérias primas alternativas (trigo, cevada, triticale) e alimentos comumente utilizados (milho e farelo de soja). Como as enzimas são bastante específicas, normalmente, os produtos comerciais que possuem uma só enzima são insuficientes para produzir o máximo benefício, fazendo com que os estudos realizados sejam quase que inteiramente com complexos enzimáticos (TEJEDOR et al., 2001a).

Os fatores que interferem no desempenho animal em resposta a suplementação enzimática são: o genótipo do cereal e suas condições de crescimento, a idade do animal, o processamento e a densidade nutricional da dieta, a dose utilizada da enzima (PONTE et al., 2004a) e a conservação da dieta após o processamento.

Alguns trabalhos têm comprovado a eficácia do uso de enzimas, entretanto ainda não há consenso na literatura, principalmente pela diversidade de metodologias empregadas nos ensaios, o que, em muitos casos, até mesmo inviabiliza a comparação entre os dados obtidos em alguns estudos. 
Araújo, D.M. Alternativos em nutrição e alimentação de aves. PUBVET, Londrina, V. 2, N. 46, Art\#451, Nov3, 2008.

\subsection{FITASE}

A maior parte das dietas mundialmente ofertadas para as aves é composta de ingredientes de origem vegetal e, conforme TEJEDOR et al. (2001b), a maior parte do fósforo presente nestes ingredientes encontrase complexado na molécula de ácido fítico, que é indisponível para aves. Apenas cerca de um terço do fósforo total destes alimentos é aproveitado pelas aves e suínos. Isto se deve ao fato do fósforo encontrar-se combinado ao inositol, formando a molécula do ácido fítico ou hexafosfato de inositol, que é pouco disponível aos animais monogástricos, pois estes não dispõem da enzima fitase para aproveitá-lo (YAN et al., 2003; COSTA et al., 2004; YAN et al., 2004).

Além do fósforo, a molécula de fitato pode formar quelatos com outros minerais, como os cátions divalentes, cálcio, zinco, cobre, ferro, potássio, magnésio e manganês (SCHOULTEN et al., 2003).

Devido à presença deste fator antinutricional (para os animais monogástricos) nos alimentos de origem vegetal, torna-se imprescindível a suplementação da ração com uma fonte inorgânica de fósforo, proporcionando valores deste mineral acima das exigências do animal como margem de segurança (LUDKE et al., 2002), o que eleva ainda mais a excreção fecal de fósforo e o custo das rações.

A lixiviação do fósforo, a partir das excretas das aves e outros animais domésticos, pode causar poluição da água de superfície e lençóis freáticos, tornando-se um grave problema ambiental, que pode ser minimizado com o uso da fitase exógena (SHELTON et al., 2004; COSTA et al., 2004). Devido a isto, meios efetivos e econômicos de limitar excreção de fósforo, sem perda de desempenho, são de importância vital (YAN et al., 2003; 2004; HATTEN et al., 2001).

A enzima fitase, produzida comercialmente a partir de microorganismos do gênero Aspergillus, tem sido utilizada, muitas vezes com sucesso, nas rações de aves e suínos, para aumentar a disponibilidade de fósforo, complexado na molécula do fitato, além disto, 
Araújo, D.M. Alternativos em nutrição e alimentação de aves. PUBVET, Londrina, V. 2, N. 46, Art\#451, Nov3, 2008.

possui outros efeitos (Tabela 1) e tem possibilitado um aumento na disponibilidade de outros minerais, além de aumentar o valor energético das dietas, embora alguns resultados ainda sejam controversos.

Além de disponibilizar o fósforo complexado, a enzima fitase pode se tornar importante também por diminuir o uso do fósforo inorgânico e reduzir a margem de segurança, fazendo com que o nível de excreção fecal seja minimizado.

Tabela 1 - Efeitos benéficos da suplementação com fitase

\begin{tabular}{|c|c|c|}
\hline Age Sobre & Ação & Condições \\
\hline$P$ & $\begin{array}{l}\text { Reduz a excreção e } \\
\text { melhora a estrutura óssea } \\
\text { de frangos }\end{array}$ & $\begin{array}{l}\text { Fósforo "não-fítico" } \\
\text { entre } 0,15 \text { e } 0,45 \%\end{array}$ \\
\hline $\mathrm{Zn}, \mathrm{Ca}, \mathrm{N}$ & Melhora a Retenção & $\begin{array}{l}\text { Fósforo "não-fítico" } \\
\text { entre } 27 \text { a } 54 \% \text { em } \\
\text { relação ao P total }\end{array}$ \\
\hline $\mathrm{Ca}, \mathrm{Mg}, \mathrm{Fe}, \mathrm{Zn}, \mathrm{Cu}$ & Melhora a Retenção & $\begin{array}{l}\text { Fósforo "não-fítico" } \\
\text { entre } 0,11 \text { a } 0,26 \%\end{array}$ \\
\hline
\end{tabular}


Araújo, D.M. Alternativos em nutrição e alimentação de aves. PUBVET, Londrina, V. 2, N. 46, Art\#451, Nov3, 2008.

\section{8. ÁCIDOS ORGÂNICOS}

Os ácidos orgânicos têm efeito inibidor da proliferação de enterobactérias indesejáveis e potencializa os ganhos nutricionais das dietas pelo aumento da disponibilidade de nutrientes para as aves (PENZ JÚNIOR, 1993). Estas substâncias possuem efeito positivo na flora intestinal e/ou no desenvolvimento intestinal (IMMERSEEL et al., 2004).

Ácidos orgânicos são substâncias que contêm uma ou mais carboxilas em sua molécula (HART e SCHUETZ, citados por PENZ JÚNIOR et al., 1993). Em geral, quando o termo ácido orgânico é empregado na produção animal, refere-se aos ácidos fracos de cadeia curta (C1-C7), que produzem menor quantidade de prótons por molécula ao se dissociarem. A manutenção da integridade e melhoria na digestão se dá justamente pela limitação da proliferação de microorganismos patogênicos ou "nocivos". Por serem expressos logaritimicamente, uma unidade de $\mathrm{pH}$ acima do pKa de um ácido indica que $90 \%$ do ácido encontra-se na forma não dissociada e, com duas unidades de $\mathrm{pH}$ acima do $\mathrm{pKa}, 99 \%$ do ácido estará não dissociado. Isso é particularmente importante no processo digestivo, pois na dependência do $\mathrm{pH}$ dos compartimentos digestivos haverá ação ou não do ácido em questão (BELLAVER e SCHEUMERMANN, 2004).

Segundo EDMONDS et al. (1985); OKADA (1996) e FISCHER (1995), o ácido fumárico, em níveis de 0,5\% a 2\% nas rações, melhora o desempenho de aves de corte e de postura. De acordo com Lückstädt et al. (2004) a adição de um produto comercial que com a combinação entre ácido fórmico e ácido propiônico aumentou o ganho de peso de frangos de corte.

Entretanto, é difícil prever as completas interações que podem se dar entre ácidos orgânicos e outros componentes do alimento, 
Araújo, D.M. Alternativos em nutrição e alimentação de aves. PUBVET, Londrina, V. 2, N. 46, Art\#451, Nov3, 2008.

assim como a influência destes no metabolismo animal e na microflora entérica (RODRÍGUEZ-PALENZUELA, 2005).

\section{CONCLUSÃO}

A nutrição animal é bastante dinâmica, sempre lança mão de novas estratégias para melhorar o aproveitamento dos nutrientes dietéticos, na tentativa de assegurar condições para que os animais expressem o seu máximo potencial genético de produção de carne e ovos, sem que haja acréscimos aos custos de produção.

Para tanto, o uso de alternativas como os modernos produtos da biotecnologia: enzimas, probióticos, prebióticos, simbióticos e ácidos orgânicos, assumem importância significativa para a avicultura brasileira.

\section{REFERÊNCIAS BIBLIOGRAFICAS}

BEDFORD, M. R. Exogenous enzymes in monogastric nutrition-their current value and future benefits. Animal Feed Science and Technology, v.86, n.1-13, 2000.

BELLAVER, C.; SCHEUERMANN, G. Aplicações dos ácidos orgânicos na produção de aves de corte. III Seminário Internacional de Aves e Suínos, Florianópolis-SC, AveSui 2004. Capturado em: 19 de março. 2005. Online. http://www.aviculturaindustrial.com.br/.

CAFÉ, M.B. et al. Avizyme Improves Performance of Broilers Fed CornSoybean Meal-Based Diets. Journal of Applied Poultry Research. Savoy, v.11, n.1, p. 29-33, 2002.

CHAMBERS, J.R.; LU, X. Probiotics and Maternal Vaccination for Salmonella Control in Broiler Chickens. Journal of Applied Poultry Research, Savoy, v.11, n.3, p. 320-327, 2002.

COOK, M. E. Antibodies: Alternatives to Antibiotics in Improving Growth and Feed Efficiency. Journal of Applied Poultry Research, Savoy, v.13, n.1, p.106-119, 2004.

CORRÊA et al. Digestibilidade da Ração de Frangos de Corte Suplementados com Probióticos e Antibiótico. Ciência Rural, Santa Maria, v.32, n.4, p.687-691, 2002.

COSTA, F.G.P. et al. Utilização de um Complexo Multienzimático em Dietas de Frangos de Corte. Ciência Animal Brasileira, Goiânia, v.5, n.2, p. 63-71, 2004. 
Araújo, D.M. Alternativos em nutrição e alimentação de aves. PUBVET, Londrina, V. 2, N. 46, Art\#451, Nov3, 2008.

DIONIZIO, M.A. et al. Prebióticos como Promotores de Crescimento para Frangos de Corte - Desempenho e Rendimento de Carcaça. Ciência e Agrotecnologia, Lavras, Ed. Especial, p.1580-1587, 2002.

EDMONDS, S. M. et al. Feeds additives studies whit newly weaned pigs: efficacy of supplemental. Copper, antibiotics and organic acids. Journal of Animal Science, Savoy, v.60, n.2, p.936-938, 1995.

FISHER, D.A. et al. Utilização do ácido fumárico na prevenção do estresse calórico e síndrome de morte súbita em frangos de corte. Agrárias, v.14, n.1-2, p.77-82, 1995.

FISCHER, G. et al. Desempenho de Frangos de Corte Alimentados com Dietas à Base de Milho e Farelo de Soja, com ou sem Adição de Enzimas. Revista Brasileira de Zootecnia, Brasília, v.31, n.1 (SUPL) p.402-410, 2002.

FRITTS, C. A. et al. Bacillus Subtilis C-3102 (Calsporin) Improves Live Performance And Microbiological Status of Broiler Chickens. Journal of Applied Poultry Research, Savoy, v.9, n.2, p.149-155, 2000.

HATTEN, L. F.; INGRAM III, D. R.; PITTMAN, S. T. Effect of Phytase on Production Parameters and Nutrient Availability in Broilers and Laying Hens: A Review. Journal of Applied Poultry Research, Savoy, v.10, n.1, p. 274-278, 2001.

HOOGE, D.M. et al. Effect of Dietary Mannan Oligosaccharide, With or Without Bacitracin or Virguniamycin, on Live Performance of Broiler Chickens at Relatively High Stocking Density on New Litter. The Journal of Applied Poultry Research, Savoy, v.12, n.4, p. 461-467, 2003.

HRUBY, M. et al. Estratégias Nutricionais Frente Ao Desafio de Um Mercado de Frangos em Rápida Transformação. V SIMPÓSIO BRASIL SUL DE AVICULTURA. 05 a 07 de abril de 2004, Chapecó - SC, Brasil. ANAIS...

HU, J.; FULLER, L.; McDOUGALD, L.R. Do Anticoccidials Interfere With Developement of Protective Immunity Against Coccidiosis in Broilers? Journal of Applied Poultry Research, Savoy, v.9, n.3, p.352-358, 2000.

IMMERSEEL, F.V. et al. Feed Additives to Control Salmonella in Poultry. Worlds Poultry Science Journal, v.58, n.4, p.501-513, 2004.

LESSON, S. et al. Commercial Enzymes and Their Influence on Broilers Fed Wheat or Barley. Journal of Applied Poultry Research. v.9, n.2, p.242-251, 2000.

LODDI, M.M. et al. Uso de probiótico e antibiótico sobre o desempenho, o rendimento e a qualidade de carcaça de frangos de corte. Revista Brasileira de Zootecnia, v.29, n.4, p.1124-1131, 2000.

LUCHESI, J.B.; JUSTINO, E. Matérias Primas Alternativas na Alimentação de Frangos de Corte e Matrizes. CONFERÊNCIA APINCO DE CIÊNCIA E TECNOLOGIA AVÍCOLAS, Campinas-SP, FACTA, 2003. p.137-167.

LÜCKSTÄDT, C.; ŞENKÖYLÜ, N.; AKYÜREK, H.; AĜMA, A. ACIDIFIER - A MODERN ALTERNATIVE FOR ANTI-BIOTIC FREE FEEDING IN LIVESTOCK PRODUCTION, WITH SPECIAL FOCUS ON BROILER PRODUCTION. VETERINARIJA IR ZOOTECHNIKA. T. 27 (49). p.91-93, 2004. 
Araújo, D.M. Alternativos em nutrição e alimentação de aves. PUBVET, Londrina, V. 2, N. 46, Art\#451, Nov3, 2008.

LUDKE, M.C.M.M. et al. Utilização da fitase em dietas com ou sem farelo de arroz desengordurado para suínos em crescimento/terminação. Revista Brasileira de Zootecnia, v.31, n.4, p.2002-2010, 2002.

MAIORKA, A. et al. Utilização de Prebióticos, Probióticos ou Simbióticos em Dietas para Frangos. Revista Brasileira de Ciência Avícola, v.3, n.1, p.75-82, 2001.

OKADA, A. K. et al. Adição de ácido orgânico (ácido fumárico) nas rações de poedeiras. In: CONFERÊNCIA APINCO DE CIÊNCIA E TECNOLOGIA AVÍCOLA, 1996, Curitiba. Anais... Campinas: FACTA, 1996. p.33.

PENZ JÚNIOR, A. M. Ácidos orgânicos na alimentação de aves. In: CONFERÊNCIA APINCO DE CIÊNCIA E TECNOLOGIA AVÍCOLAS, 1993, Santos-SP. Anais... Campinas-SP: FACTA, 1993. p.111-119.

PERSIA, M.E.; DEHORITY, B.A.; LILBURN, M.S. The effects of Enzyme Supplementation of Corn- and Wheat-Based Diets on Nutrient Digestion and Cecal Microbial Populations in Turkeys. Journal of Applied Poultry Research. v.11, n.3, p.320-327, 2002.

PONTE, P.I.P. et al. Xylanase Inhibitors Affect the Action of Exogenous Enzymes Used to Supplement Triticum durum-Based Diets for Broiler Chicks. Journal of Applied Poultry Research. v.13, n.4, p. 660-666, 2004a.

PONTE, P.I.P. et al. Use of Cellulases and Xylanases to Supplement Diets Containing Alfafa for Broiler Chicks: Effects on Bird Performance and Skin Color. Journal of Applied Poultry Research. v.13, n.3, p. 412-420, 2004b.

PUCCI, L.E.A. et al. Níveis de óleo e adição de complexo enzimático na ração de frangos de corte. Revista Brasileira de Zootecnia, Brasília, v.32, n.4, p.909-917, 2003.

RODRÍGUEZ-PALENZUELA, P. LOS ÁCIDOS ORGÁNICOS COMO AGENTES ANTIMICROBIANOS. Capturado em $15 \mathrm{de}$ fev. 2005. Disponível na internet. Online. http://www.etsia.upm.es/fedna/capitulos/00CAP8.pdf.

SATO, R.N.; LODDI, M.M.; NAKAGHI, L.S.O. Uso de Antibiótico e/ou Probiótico como Promotores de Crescimento em Rações Iniciais de Frangos. Revista Brasileira de Ciência Avícola, v.37, n.4, Supl, 2002.

SANTOS, W.G. et al. Manose na Alimentação de Leitões na Fase de Creche (Desempenho, pH do Trato Gastrintestinal e Peso dos Órgãos). Ciência e Agrotecnologia, Lavras, v.27, n.3, p.696-702, 2003.

SARTORI, J.R. et al. Silagem de grãos úmidos de milho na alimentação de frangos de corte. Pesquisa Agropecuária Brasileira, v.37, n.7, Brasília, 2002.

SCAPINELLO, C. et al. Effect of the utilization of oligosaccharide mannose and acidifiers on growing rabbits performance. Revista Brasileira de Zootecnia, Brasília, v.30, n.4, p.1272-1277, 2001.

SHELTON, J.L. et al. Evaluation of the Nutriente Matrix Values for Phytase in Broilers. Journal of Applied Poultry Research, v.13, n.2, p. 213-221, 2004.

SCHOULTEN, N.A. et al. Níveis de cálcio em rações de frangos de corte na fase inicial suplementadas com fitase. Revista Brasileira de Zootecnia, Brasília, v.32, n.5, p.1190-1197, 2003. 
Araújo, D.M. Alternativos em nutrição e alimentação de aves. PUBVET, Londrina, V. 2, N. 46, Art\#451, Nov3, 2008.

SILVA, J.H.V.; JORDÃO FILHO, J.; SILVA, E.L. Efeito do alho (Allium sativum Linn.), probiótico e virginiamicina antes, durante e após o estresse induzido pela muda forçada em poedeiras semipesadas. Revista Brasileira de Zootecnia. v.32, n.6, supl.1, p.1697-1704, 2003.

SILVA, L.P.; NÖRNBERG, J.L. Prebióticos na nutrição de não ruminantes. Ciência Rural, Santa Maria, v.33, n.5, p.983-990, 2003.

TEJEDOR, A.A. et al. Efeito da adição de enzimas em dietas de frangos de corte à base de milho e farelo de soja sobre a digestibilidade ileal de nutrientes. Revista Brasileira de Zootecnia, Brasília, v.30, n.3, p.809-816, 2001a.

TEJEDOR, A.A. et al. Efeito da adição da enzima fitase sobre o desempenho e a digestibilidade ileal de nutrientes. Revista Brasileira de Zootecnia, Brasília, v.30, n.3, p.802-808, 2001b.

YAN F. et al. Evaluation of Modified Dietary Phosforus Levels With and Without Fitase Supplementation on Live Performance and Fecal Phosphorus Levels in Broiler Diets. 1. Full-term Feeding Recommendations. Journal of Applied Poultry Research, v.12, n.2, 2003.

YAN, F.; FRITTS C.A.; WALDROUP, P.W Evaluation of Modified Dietary Phosphorus Levels with and Without Phytase Supplementation on Live Performance and Excreta Phosphorus Concentration in Broiler Diets. 2. Modified Early Phosphorus Levels. Journal of Applied Poultry Research, v.13, n.3, p. 394-400, 2004. 